\title{
Improvement of Islet Engrafts by Enhanced Angiogenesis and Microparticle-Mediated Oxygenation
}

Leila Montazeri $^{\mathrm{a}}$, Shahriar Hojjati-Emami ${ }^{\mathrm{a},{ }^{*}}$, Shahin Bonakdar $^{\mathrm{b}}$, Yaser Tahamtani ${ }^{\mathrm{c}}$, Ensiyeh Hajizadeh-Saffar ${ }^{\mathrm{c}}$, Marjan Noori-Keshtkar ${ }^{\mathrm{c}}$, Mostafa Najar-Asl ${ }^{\mathrm{c}}$, Mohammad Kazemi Ashtiani ${ }^{\mathrm{c}}$, Hossein Baharvand, ${ }^{\mathrm{c},{ }^{* *}}$

${ }^{\text {a }}$ Department of Biomedical Engineering, Amirkabir University of Technology, Tehran, Iran

${ }^{\mathrm{b}}$ National Cell Bank, Pasteur Institute of Iran, Tehran, Iran

${ }^{c}$ Department of Stem Cells and Developmental Biology, Cell Science Research Center, Royan Institute for Stem Cell Biology and Technology, ACECR, Tehran, Iran

${ }^{\mathrm{d}}$ Department of Developmental Biology, University of Science and Culture, ACECR, Tehran, Iran

\section{Corresponding authors:}

${ }^{* * *}$ Hossein Baharvand

Email: Baharvand@Royaninstitute.org

and

*Shahriar Hojjati-Emami

Email: semami@aut.ac.ir

Author contributions: L.M., S.B., Y.T., and H.B. designed the research; L.M., E.H.S., M.N.K, and M.N.A performed the research; L.M., E.H.S., Y.T., and H.B. performed data analyses; L.M., S.B., Y.T., E.H.S., M.K.A., S.H.E., and H.B. wrote the manuscript. 
Running title: Increased Islet Engrafts by Angiogenesis and Oxygen generator MP

Competing financial interests: The authors declare they have no competing financial interests. 
Keywords: Diabetes, Islet transplantation, Oxygen-generating microparticle, Angiogenesis 


\section{Introduction}

Transplantation of isolated islets of Langerhans is an emerging, promising treatment for type 1 diabetes mellitus (T1D) [1]. Recent advances have increased the yield of insulin independency by up to $44 \%$, following three years of islet transplantation [2]. However, several shortcomings still restrict the mode of progression (reviewed in [3]), such as the lack of oxygen which can lead to impairment of islet function and death during the early post-transplantation period [4].

Under normal conditions, glucose-stimulated insulin secretion (GSIS) depends on oxidative phosphorylation. Pyruvate is produced from glucose uptake through glycolysis and utilized in the production of adenosine triphosphate (ATP) via mitochondrial oxidative pathways [5]. In contrast, hypoxia alters aerobic glucose metabolism to anaerobic glycolysis and attenuates GSIS [6], finally leading to activation of caspase-3 and apoptosis of islet cells [7].

Although under hypoxic conditions, activation of HIF in islet cells induces the secretion of angiogenic factors such as vascular endothelial growth factor (VEGF) [6]. According to research, the endogenous angiogenic factors produced by transplanted islets are inadequate to induce angiogenesis during the early post-transplant period [8]. Therefore, it is necessary to protect islets from the irreversible damaging effects of hypoxia prior to blood vessel formation [9]. Mechanisms utilized to supply oxygen during the early post-transplant period include the use of a prevascularized device-less site [10], induction of angiogenic factors over-expressed by islets or helper cells [11, 12], and proangiogenic factors concomitant with transplanted islets [13, 14]. Other approaches directly oxygenate the transplant site such as in situ generation of oxygen with hydration of solid peroxide [9], the use of a device that consists of a minimally invasive implantable chamber to supply oxygen [15], application of oxygen carrier agents such as hemoglobin [16], and perfluorocarbons accompanied by islets [16, 17]. 
In this study, we generated oxygen-generating microparticles (MP) with a core-shell structure composed of a polyvinylpyrrolidone (PVP)/ $\mathrm{H}_{2} \mathrm{O}_{2}$ core and a poly(lactide-co-glycolide) PLGA shell that was coated with immobilized catalase enzyme on the surface of the MP in order to provide sustained release of oxygen. Carboxyl-end groups of PLGA were activated to bind with the tetrameric structure of the catalase, which allowed the enzyme to remain in its active form for at least two weeks $[18,19]$ in order to decompose $\mathrm{H}_{2} \mathrm{O}_{2}$ upon its release from the MP. For induction of angiogenesis, we generated a composite scaffold composed of a collagen sponge as the frame and fibrin-conjugated heparin/VEGF as the sustained delivery system for VEGF. This scaffold composition was reported to be appropriate for angiogenesis [20]. Short-term delivery of VEGF was more effective via this approach [21]. We investigated the impact of combined oxygenation and angiogenesis induction on the outcome of the islet grafts.

\section{Materials and methods}

\subsection{Materials and chemicals}

All chemicals were purchased from Sigma-Aldrich unless otherwise noted.

\subsection{Oxygen-generating microparticles (MP)}

\subsubsection{Fabrication of core-shell structural MP}

$\mathrm{H}_{2} \mathrm{O}_{2}$ was mixed with PVP at a molar ratio of 3:1 [repeating unit N-vinylpyrrolidone (VP)] and stirred overnight at $4{ }^{\circ} \mathrm{C}$ in order to obtain a uniform mixture. The core-shell microspheres were fabricated by homogenizing PVP/ $\mathrm{H}_{2} \mathrm{O}_{2}$ in a PLGA (RG $504 \mathrm{H}$, Boehringer Ingelheim, Germany) solution (5\% weight in dichloromethane) with a 1:25 (V/V) ratio at $26000 \mathrm{rpm}$ for $3 \mathrm{~min}$. Phase separation was induced upon addition of olive oil that contained Span $80(4 \% \mathrm{~V} / \mathrm{V})$ at a $6: 1$ 
(V/V) ratio and homogenized at $20000 \mathrm{rpm}$ for $1 \mathrm{~min}$. The coacervate polymer droplets that surrounded $\mathrm{PVP} / \mathrm{H}_{2} \mathrm{O}_{2}$ were hardened in n-heptane for $3 \mathrm{~h}$. The particles were washed three times in n-heptane, centrifuged at $1000 \mathrm{rpm}$, and vacuum dried.

\subsubsection{Immobilization of catalase on the MP surface}

MP (5 mg) were suspended in $1 \mathrm{ml}$ of a $10 \mathrm{mM}$ N-(3-dimethylaminopropyl)-N'ethylcarbodiimide hydrochloride/N-Hydroxysuccinimide (EDC/NHS) solution for $2 \mathrm{~h}$ under continuous stirring, and then washed three times with distilled water. Afterwards, the activated particles were added to a $2 \mathrm{mg} / \mathrm{ml}$ catalase (obtained from bovine liver) solution in phosphatebuffered saline (PBS; Gibco, USA), shaken for $2 \mathrm{~h}$ and washed three times with PBS. All procedures were performed at room temperature. MP were analyzed by FTIR spectroscopy (EQUINOX55, Germany) and scanning electron microscopy (SEM, TESCAN, Czech Republic). A fluorometric procedure (Invitrogen Qubit fluorometer, USA) was used to evaluate the efficiency of catalase immobilization by subtracting the amount of protein in the initial solution from the supernatant and washing solution.

\subsubsection{Determination of catalase activity and kinetic parameters}

Standard solutions of $\mathrm{H}_{2} \mathrm{O}_{2}(5-30 \mathrm{mM})$ were prepared and their absorbance at $240 \mathrm{~nm}$ determined. The ability of immobilized catalase to decompose the $\mathrm{H}_{2} \mathrm{O}_{2}$ solution was quantified by measuring the reduction in absorbance of $\mathrm{H}_{2} \mathrm{O}_{2}$. One unit of activity was considered as the decomposition of $\mathrm{H}_{2} \mathrm{O}_{2}$ at a rate of $1 \mu \mathrm{mol} / \mathrm{min}$ at $25^{\circ} \mathrm{C}$ and $\mathrm{pH}$ 7. Activity of immobilized catalase was measured by a UV-Vis spectrophotometer (Biochrom WPA Biowave II, United Kingdom). The influence of substrate concentration on the activity was verified by utilizing 
different concentrations of $\mathrm{H}_{2} \mathrm{O}_{2}$ at constant temperature and $\mathrm{pH}$. Kinetic parameters $\left(\mathrm{K}_{\mathrm{m}}\right.$ and $\mathrm{V}_{\max }$ ) of free and immobilized enzyme were determined by Lineweaver-Burk plots [22].

\subsubsection{Measurement of generated oxygen}

We measured the amount of oxygen produced over a 14-day period from MP $(1 \mathrm{mg} / \mathrm{ml})$ using a non-invasive, ruthenium-based oxygen sensor (PreSens, Germany). MP were in an unsealed vial that contained PBS in a $37^{\circ} \mathrm{C}$ humidified incubator at normal oxygen tension.

\subsection{Cell culture studies}

A total of $3 \times 10^{3}$ MIN6 cells (a generous gift from Professor Harry Heimberg; Virije Universiteit Brusse) were seeded on a 24-well plate (Nunc, Denmark) in Dulbecco's modified eagle medium (DMEM) that contained 10\% fetal bovine serum (FBS; Gibco, USA), $100 \mathrm{U} / \mathrm{ml}$ penicillin and $100 \mu \mathrm{g} / \mathrm{ml}$ streptomycin. The four experimental groups were defined as follows: two hypoxia groups that were incubated at 5\% oxygen tension, one group with MP and one group without MP. The other two groups were incubated at normal oxygen tension in the presence or absence of MP. The two groups with MP received $3 \mathrm{mg} / \mathrm{ml}$ of MP. After 7 days of incubation, the supernatants were assessed for LDH by an enzyme-linked immunosorbent assay (ELISA) kit (Biorexfars, United Kingdom). In addition, seeded cells were analyzed for DNA content, the MTS (Promega, USA) assay and HIF1- $\alpha$ immunofluorescence staining (Biorbyt, orb69409, USA). All experiments were performed in triplicate.

\subsection{Angiogenic scaffold}

\subsubsection{Preparation fibrinogen-conjugated heparin}


Carbodiimide chemistry was used to create the fibrinogen-conjugated heparin structure. Carboxylic acid groups of heparin were activated in an EDC/NHS (1 mM) solution for $2 \mathrm{~h}$ at $25^{\circ} \mathrm{C}$. The activated heparin was precipitated with excess anhydrous acetone and lyophilized. Fibrinogen was dissolved in PBS $(5 \mathrm{mg} / \mathrm{ml})$ and we added activated heparin $(3 \mathrm{mg} / \mathrm{ml})$ to this solution. Afterwards, in order to bond the amine groups of fibrinogen to activated carboxylic acid groups of heparin, the mixture was maintained for $3 \mathrm{~h}$ at $4^{\circ} \mathrm{C}$ with stirring. The fibrinogenheparin solution was filtered through an Amicon Ultra-15 centrifugal filter (30 kDa; Millipore, USA) to remove any residual heparin. The filtered solution was lyophilized in liquid nitrogen [23]. FTIR spectroscopy was used to confirm the conjugation and dimethylmethylene blue (DMMB) staining was performed for evaluation of heparin conjugation efficiency.

\subsubsection{Fabrication of collagen based scaffold}

Type I collagen from rat tail tendon was prepared according to a previously published protocol [24]. The collagen solution $(5 \mathrm{mg} / \mathrm{ml})$ in acid acetic $(50 \mathrm{mM})$ was neutralized by sodium hydroxide $(1 \mathrm{~N})$, poured into a mold (diameter: $8 \mathrm{~mm}$, depth: $3 \mathrm{~mm}$ ), frozen at $-20^{\circ} \mathrm{C}$ and freezedried for $24 \mathrm{~h}$. Cross-linking of the collagen scaffold was carried out by EDC/NHS (50 mM) in an ethanol (70\%) solution for $6 \mathrm{~h}$. The scaffold was washed three times with distilled water and freeze-dried for $24 \mathrm{~h}$. In order to fabricate a construct containing fibrin-heparin/VEGF collagen, fibrinogen $(24 \mathrm{mg} / \mathrm{ml}, 60 \%)$, fibrinogen conjugated heparin $(16 \mathrm{mg} / \mathrm{ml}, 40 \%)$ and VEGF (100 $\mathrm{ng} / \mathrm{ml}, 37^{\circ} \mathrm{C}$ ) were diluted in DMEM (1:1). In addition, thrombin (90 IU) was dissolved in a calcium chloride solution $(6 \mathrm{mg} / \mathrm{mL})$. Next, we injected the fibrinogen mixture solution into the collagen sponge after injection of the thrombin solution. 


\subsubsection{Determination of VEGF release kinetics}

The release kinetics of VEGF from the scaffolds was evaluated for two weeks. Scaffolds in triplicate were soaked in PBS under continuous agitation at $37^{\circ} \mathrm{C}$. The amount of released VEGF in the supernatant at specified intervals was measured by an ELISA kit (Invitrogen, USA) and expressed as cumulative percentage of the total amount of loaded growth factor.

\subsubsection{Tube formation assay}

Tube formation assay was performed by coating Matrigel $(10 \mathrm{mg} / \mathrm{ml})$ on a 96- well plate. Human umbilical vein endothelial cells (HUVECS) were isolated according to a previously reported protocol and cultured in endothelial growth medium (Lonza, Switzerland) [25]. Suspended HUVECs $\left(25 \times 10^{3}\right)$ accompanied by released VEGF (days 1, 4, 7), soluble VEGF at a concentration equal to day 1 released VEGF, and PBS as the negative control were added to each well. The plate was incubated for $18 \mathrm{~h}$ at $37^{\circ} \mathrm{C}$ after which acridine orange was used for staining viable cells. Tube formation was investigated with a fluorescent microscope (Olympus BX51, Olympus, USA) and quantified as tube area $\left(\mu \mathrm{m}^{2}\right)$ per field by image analysis software (Image $\mathrm{J}$, USA) [26].

\subsubsection{Subcutaneous transplantation and characterization}

We compared the angiogenic potential of the fibrin/VEGF collagen scaffold with and without heparin in vivo. Scaffolds were transplanted subcutaneously in the flanks of C57BL/6J mice ( $\mathrm{n}=3$ mice per group). Subcutaneously implanted scaffolds were harvested after 2 weeks and stained according to standard procedures of the Royan Institute Histopathology Laboratory. The samples were fixed in $10 \%$ buffered formalin, dehydrated, and embedded in paraffin blocks. The tissue 
blocks were sectioned into $5 \mu \mathrm{m}$ sections and stained with haematoxylin and eosin (H\&E). Scaffold vascularization was determined by calculating the area per vessel. We evaluated five tissue sections at $70 \mu \mathrm{m}$ intervals and divided the total vessel area (measured by Image J) by the number of vessels per field $(40 \times)$.

\subsection{Islet transplantation studies}

\subsubsection{Transplantation of the islet-containing scaffold}

Wistar rats (Pasteur Institute, Iran) pancreatic islet isolation, assessment and T1D induction in nude mice (B6NU, provided from Pasteur Institute) were carried out according to our previously published protocols [11]. In order to place islets in the scaffold, 250 islet equivalents (IEQ) were suspended in DMEM and added to the fibrinogen mixture solution as previously described, then injected into five different points of the porous collagen scaffold. Transplantation was performed in the omental pouches of anesthetized recipient mice according to our previously published protocol [11]. Recipient mice were divided into four experimental groups based on the components which were accompanied by 250 IEQ within the scaffold: I) islet, II) islet/MP, III) islet/VEGF, and IV) islet/VEGF/MP. Prior to injection into the collagen sponge, MP were suspended in DMEM while VEGF was added to the fibrinogen-heparin solution in PBS. The remaining two groups comprised the: V) sham group which underwent transplantation and did not receive islets, and VI) normal group of mice with the same weights and normoglycemic conditions, but did not undergo any transplantation. All animal experiments were carried out according to the NIH Guidelines for the Care and Use of Laboratory Animals (NIH Publication No. 85-23, revised 2010) after approval by the Royan Institute Ethics Committee. 


\subsubsection{Evaluating function of the islet-containing scaffold}

The function of transplanted islets was evaluated by measuring non-fasting blood glucose levels and body weight during four weeks after transplantation. The percentage and time to normoglycemia (blood glucose $\leq 250 \mathrm{mg} / \mathrm{dl}$ ) in mice and other factors were considered. On day 30 post-alloxan injection (PAI) we measured serum C-peptide levels with an enzyme immunoassay kit (Alpco Diagnostics, USA) and performed the intraperitoneal glucose tolerance test (IP-GTT). IP-GTT was conducted according to the following steps: after a six-hour fast period, each mouse received an intraperitoneal injection of $50 \%$ dextrose in Ringer's solution at $2 \mathrm{~g} / \mathrm{kg}$ body weight. Tail tip blood glucose levels were measured at $0,15,30,60,90$, and 120 min post-injection by an Accu-Check glucometer (Roche Diagnostics, USA) and the area under the IP-GTT curve (AUC) was determined. In order to confirm the function of the transplanted islets, the scaffolds containing islets were harvested and blood glucose as an indicator of returning T1D was measured.

\subsection{Statistical analysis}

Data were presented as mean \pm standard deviation (SD). Statistical significance was tested by SPSS software (version 16) using one-way analysis of variance (ANOVA) followed by Bonferoni's post-hoc test. The trends of changes between groups during the measured time points were compared using the general linear model. Differences were considered significant at $P$-values less than 0.05 .

Details of the methods can be found in the SI Materials and Methods.

\section{Results}




\subsection{MP produced oxygen for two weeks}

We used the coacervation method to prepare MP that consisted of a $\mathrm{PVP} / \mathrm{H}_{2} \mathrm{O}_{2}$ core and PLGA shell (Fig. 1A). PLGA carboxylic acid end groups were used to immobilize catalase enzyme on the surface of the MP that would decompose the released $\mathrm{H}_{2} \mathrm{O}_{2}$. SEM analysis of their spherical morphology showed that the MP had a mean diameter of $3.5 \pm 1.9 \mu$ m (Fig. 1B and C). We performed potassium iodide staining to determine the efficiency of $\mathrm{PVP} / \mathrm{H}_{2} \mathrm{O}_{2}$ entrapment, which showed $38 \pm 2 \%$ efficiency. The carboxylic acid end groups of the PLGA chains were activated by EDC for bonding with the catalase tetramer structure and $229.3 \pm 26.6 \mathrm{mg}$ catalase/g of MP was immobilized. Conjugation of catalase on the surface preserved enzyme functionality up to $40 \%$ for 14 days (Fig. 1D) and altered the enzyme kinetic parameters $\left(K_{m}\right.$ and $\left.V_{\max }\right)$ compared to the free mode. Kinetic parameters at constant temperature, $\mathrm{pH}$ and various $\mathrm{H}_{2} \mathrm{O}_{2}$ concentrations were evaluated according to Lineweaver-Burk plots (Fig. 1E and F). Involvement of enzyme amine groups in covalent bonding altered $\mathrm{K}_{\mathrm{m}}$ from 47.6 to $66 \mathrm{mM}$ and $\mathrm{V}_{\max }$ from 5882 to 250 $\mu$ mole/(min mg protein). The Fourier transform infrared spectroscopy (FTIR) spectra of crashed MP showed two carbonyl bonds attributed to PLGA $\left(1756 \mathrm{~cm}^{-1}\right)$ and the pyrrolidone ring of $\mathrm{PVP} / \mathrm{H}_{2} \mathrm{O}_{2}\left(1656 \mathrm{~cm}^{-1}\right)$. After catalase immobilization, an amide II bond $\left(1500-1600 \mathrm{~cm}^{-1}\right)$ was observed (Fig. S1). The ability of MP (1 mg/ml) to generate oxygen over a two-week period fluctuated between $0.83 \pm 0.15$ and $0.06 \pm 0.05 \mathrm{mg} / \mathrm{l}$. PBS was the control with $6.2 \mathrm{mg} / \mathrm{l}$ soluble oxygen under normal conditions (Fig. 1G).

\subsection{Oxygen-generating MP reduced the effects of hypoxia on the MIN6 cell line and pancreatic islets}


The ability of synthesized MP to produce an adequate amount of oxygen was investigated using MIN6, a mouse beta-cell line, and pancreatic islets isolated from rats in vitro. Proliferation and alteration of the metabolic pathway in MIN6 cells were tested in the presence of MP under hypoxic conditions (5\% oxygen tension) for 7 days. Cell survival was evaluated and compared with cells cultured at normal oxygen tension (Fig. 2).

Hypoxia led to decreased viability of MIN6 cells as evidenced by decreased 3-(4,5carboxymethoxyphenyl)-2-(4-sulfophenyl)-2H-tetrazolium (MTS) level concomitant with increased lactate dehydrogenase (LDH) release (Fig. 2A and B; $P<0.005)$. However, MP (3 $\mathrm{mg} / \mathrm{ml}$ ) co-cultured with hypoxic MIN6 cells showed significant improvement in cell loss compared to those cultured without MP based on increased MTS level concomitant with decreased LDH release (Fig. $2 \mathrm{~A}$ and $\mathrm{B} ; P<0.05$ ). According to the MTS assay and based on the evaluation of LDH release, MIN6 cell survival under normoxic conditions was comparable with and without MP (Fig. 2A and B).

Hypoxic conditions activate hypoxia-inducible factor (HIF) by stabilization of the HIF- $\alpha$ moiety $[27,28]$. We observed cytoplasmic distribution of HIF- $\alpha$ in MIN6 cells cultured with MP under hypoxic conditions (Fig. 2C). Decreased cell metabolic activity and increased levels of LDH accompanied with nucleus translocation of HIF- $\alpha$ in cells cultured under hypoxic compared to normoxic conditions were symptoms of changing the metabolic pathway of MIN6 into anaerobic metabolism (Fig. 2).

Isolated rat islets were also tested under hypoxic conditions in the presence and absence of MP. According to the results, not only did MP prevent cell lysis of islets under hypoxic conditions (Fig. S2A), they also changed gene expression of the islets (Fig. S2B). According to gene expression analysis, islets without MP compared to islets with MP under hypoxic conditions 
exhibited upregulation in LDH, monocarboxylate transporter 4 (MCT4) and Glucose transferase 1 (GLUT1) in addition to slight downregulation of glucokinase (GCK). These results showed the efficacy and utility of the oxygen-generating MP for hypoxia-induced cell dysfunction and celldeath for both cell-types.

\subsection{The angiogenic scaffold promoted angiogenesis in vivo}

A porous collagen scaffold frame was generated by the freeze-dry method and cross-linked to prevent fast in vivo degradation (Fig. 3A). For sustained release, fibrinogen was covalently bonded to heparin by carbodiimide chemistry and confirmed by FTIR. FTIR analysis of fibrinogen-heparin showed one broad hydroxyl peak $\left(3200-3500 \mathrm{~cm}^{-1}\right)$ and a sulfone peak of heparin at $1050 \mathrm{~cm}^{-1}$ (Fig. S3). The amount of bonded heparin was determined by dimethyl methylene blue staining [29] and estimated to be 12\%. VEGF was added to fibrinogen-heparin and loaded in the collagen scaffold in order to produce a sustained delivery system. The kinetics of VEGF release were determined by a VEGF enzyme-linked immunosorbent assay (ELISA) kit and expressed as cumulative percentage of the total amount of loaded growth factor. The results showed that $69 \%$ of the VEGF was released from the scaffold after 2 weeks (Fig. 3B). The bioactivity of released VEGF was evaluated in vitro using the tube formation assay at days 1,4 and 7 compared to the soluble form of VEGF (with a concentration equal to the released VEGF on day 1) as the control. Tube formation was assessed by determination of the tube area per field. We observed no significant difference on days 4 and 7 compared to day 1 and the control (Fig. 3C-G). The requirement for the presence of heparin in the scaffold was determined by subcutaneous implantation of the scaffold for a two-week period. Hematoxylin and eosin (H\&E) staining of harvested scaffold sections showed penetration of the cells and generation of new 
capillaries in the fibrin-heparin/VEGF collagen scaffold. In the fibrin/VEGF collagen scaffold, this cell penetration was observed solely in the scaffold's margin (Fig. $3 \mathrm{H}$ and I). Immunohistochemistry analysis of CD31 demonstrated the presence of endothelial cells in harvested heparinized scaffold sections (Fig. 3J). We determined the area per vessel $\left(\mu \mathrm{m}^{2}\right)$, which showed that the presence of heparin in the construct resulted in a significantly higher rate of angiogenesis (Fig. 3K; $P<0.005$ ). Hence, we used the fibrin-heparin/collagen scaffold for the remainder of the experiments. Isolated islets, VEGF and MP, along with fibrinogen-heparin, were loaded into the collagen scaffold according to the four defined groups and used for further in vivo characterization (Fig. 3L and $\mathrm{M}$ ).

\subsection{Co-implantation of MP and islets within angiogenic scaffold improves graft function}

Induction of T1D and qualification of isolated murine islets were performed as previously published [11]. The in vivo experiment was undertaken by transplantation of 250 IEQ as a minimal islet mass to the omental pouch of diabetic mice [11]. To determine the effect of oxygenation and induction of angiogenesis on the improvement of islet functional tests, islets were transplanted alone or in combination with MP, VEGF, or MP/VEGF ( $\mathrm{n}=6$ per group). The average blood glucose concentration in each group of mice was checked after transplantation. Blood glucose levels showed the preliminary event of mild hypoglycemia as a result of fasting and the surgical procedure of omental transplantation of islets. The average blood glucose concentration in the group that received islet/MP/VEGF was lower compared to the islet, islet/MP groups $(P<0.005)$ and islet/VEGF group (Fig. 4A; $P<0.01)$. There was a more rapid return to normal blood glucose levels in the islet/MP/VEGF group (7.6 \pm 2.6 days) compared to the other groups (Fig. 4B; $P<0.05$ ). Mice that received islet/MP/VEGF had a positive trend 
toward weight gain, which was the same as normal mice, and significantly different compared to the other groups (Fig. 4C; $P<0.005$ ). At four weeks after transplantation, $83 \%$ of mice in the islet/MP/VEGF group returned to the state of euglycemia compared to the other groups that had lower numbers of euglycemic mice $(P<0.005)$. The IP-GTT, an index of glucose reactiveness of transplanted islets, was performed after four weeks. The results indicated that this group had a higher rate of glucose clearance compared to the other groups (Fig. 4D; $P<0.005$ ). This finding was confirmed by calculating the area under the IP-GTT curve (AUC; Fig. 4E; $P<0.005$ ). Although the C-peptide level of this group was comparable with the normal group, this value was higher than the islet/VEGF, islet and islet/MP $(P<0.005)$ groups (Fig. 4F). Induction of angiogenesis was evaluated by calculation of the area per vessel in the grafts that had been harvested four weeks after transplantation in order to determine the revascularization index. There was less revascularization in the grafts from the islet/MP/VEGF group compared to those from the islet/VEGF group. However, the grafts from the islet/MP/VEGF group had a higher amount of revascularization compared to the islet and islet/MP groups (Fig. 4G; $P<0.01$ ). Immunohistochemistry for insulin and H\&E staining of the harvested grafts in this group showed a functional islet and mature vessels located nearby (Fig. 4H).

\section{Discussion}

We sought to provide oxygen supply within an entire scaffold during the early post-transplant period by using biodegradable oxygen-generating MP, accompanied by sustained delivery of VEGF in order to enhance angiogenesis. Previously, the effect of each approach, oxygenation [9, 15] and induction angiogenesis [30,31], were separately reported. To our best knowledge, this is 
first observation that the simultaneous exposure of oxygenation and angiogenesis induction have higher improvement in engraftment of transplanted islets than each one separately.

In order to provide oxygenation during the early post-transplant period, core-shell structural MP that contained immobilized catalase on its surface was prepared. These MP were made by the coacervation method and contained PLGA as the shell. PVP/ $\mathrm{H}_{2} \mathrm{O}_{2}$ was used in the core of the MP due to the creation of a stable complex and slower $\mathrm{H}_{2} \mathrm{O}_{2}$ release rate [32, 33]. Embedding $\mathrm{H}_{2} \mathrm{O}_{2}$ or PVP/ $\mathrm{H}_{2} \mathrm{O}_{2}$ within PLGA has previously been reported by other methods. However, in order to decompose $\mathrm{H}_{2} \mathrm{O}_{2}$, these studies used either the soluble form of catalase or its combination with hydrogel $[32,34]$. Here, we immobilized catalase on the surface of MP to decompose $\mathrm{H}_{2} \mathrm{O}_{2}$ into water and oxygen. Catalase has a tetrameric structure and loses its activity at low concentrations due to dissociation of its subunits. In order to preserve catalase activity for a longer period, these quaternary structures were stabilized by covalent bonding to carboxyl groups of PLGA polymer chains on the surface of MP [35]. The immobilization procedure has been shown to change kinetic parameters due to alterations in enzyme structure, flexibility and steric hindrance of the active site [18]. Functional catalase was present during 14 days. The presence of catalase in the surface of MP led to the production of oxygen upon release of $\mathrm{H}_{2} \mathrm{O}_{2}$ and reduced the risk of cell-loss by released $\mathrm{H}_{2} \mathrm{O}_{2}$. It has been previously shown that increase in $\mathrm{H}_{2} \mathrm{O}_{2}$ concentration affects $\beta$-cell survival and function [36]. In the current system, we have measured the amount of generated oxygen per gram of MP. The fabricated MP generated oxygen in a tunable and uniform mode by using different quantities of MPs.

The active HIF transcriptional factor is a dimer that contains $\alpha$ and $\beta$ subunits. HIF $\beta$ is stable and capable of binding HIF $\alpha$ subunits. Stabilization of HIF $\alpha$ depends on hypoxic conditions due to proteasomal degradation of HIF $\alpha$ in the presence of oxygen. Therefore, decreased oxygen 
tension results in reduced HIF $\alpha$ proteasomal degradation, translocation into the nucleus, and enabling the stabilized form to dimerise with HIF $\beta$. It is followed by activation genes which impact glucose uptake, metabolism ( $\beta$ cell function) and induction of apoptosis [27, 28]. HIF activation has resulted in induction of LDH and monocarboxylate transporter-4 which convert pyruvate to lactate in an anaerobic metabolism pathway. Moreover, activated HIF altered expression of GIUT1 and GCK that changed rate of glucose uptake into the cell and its utilization [6,37]. The capability of MP to improve cell survival and preserve cell functionality was observed in vitro. The presence of MP in the simulated hypoxic environment prevented the MIN6 cell line from stabilization and translocation of HIFa to the nucleus. We observed increased cell metabolic activity as well as decreased LDH release in cells cultured under hypoxic conditions in the presence of MP compared to those cultured without MP.

Under hypoxic conditions, activation of HIF in islet cells induces the secretion of angiogenic factors such as VEGF [6]. However, it is not adequate to induce angiogenesis early after islet transplantation [8]. In order to promote angiogenesis, we have used a composite scaffold that consisted of a porous collagen sponge as a frame with fibrin-conjugated heparin for VEGF heparin-affinity based controlled release and maintenance of VEGF bioactivity [38, 39]. Previously, the efficiency of VEGF delivery in improving engraftment of transplanted islets has been reported [30, 31]. Heparin was conjugated to fibrinogen via covalent bonding of the heparin carboxyl group to the fibrinogen amine group. This combination was reported to be an efficient method for slow passive release of heparin-binding growth factor $[23,40]$.

To assess the impact of oxygenation, enhanced angiogenesis, or both, the outcome of grafted islets was investigated in vivo. Diabetic mice that received a scaffold which contained islet/MP compared with only islets showed reduction in euglycemia time and enhancement in percentage 
of euglycemic mice. According to the current study, the islet/VEGF group which received the inducing angiogenic scaffold has shown significantly improved results compared to the islet and islet/MP groups. When angiogenesis is enhanced without oxygenation by other external factors, the time that cells experience hypoxia is shortened. However, this short period of time irreversibly affects islet cell function [28, 39]. The combination of oxygen-generating MP and angiogenesis-promoting scaffold could be the ultimate goal due to maximum preservation of islet mass during the post-transplant period [9].

\section{Conclusion}

Collectively, our results showed that co-transplantation of oxygen-generating MP and minimal islet mass within fibrin-conjugated heparin/VEGF collagen scaffold has tremendous potential to improve islet revascularization, oxygenation and diabetes reversal. This improvement may be clinically useful by potential reduction of the amount of required islets and increasing the insulin independence following islet transplantation, which can be investigated in further studies. This may provide a promising avenue for other cell-based implants as well as ischemic tissues.

\section{Acknowledgments}

This study was funded by grants provided from Royan Institute, the Iranian Council of Stem Cell Research and Technology, the Iran National Science Foundation (INSF), and Iran Science Elites Federation. We express our appreciation to all members of the Cell Engineering and Beta Cell Programs at Royan Institute for their helpful deliberations and consultation during this work. We express our appreciation to Anavasadat Sadr Hashemi-Nejad and Poya Tavakol-Rad for their assistance in performing animal studies and Azadeh Moradmand for her assistance with the cell experiments. 


\section{References}

[1] McCall M, Shapiro AJ. Update on islet transplantation. Cold Spring Harbor perspectives in medicine 2012;2:a007823.

[2] Barton FB, Rickels MR, Alejandro R, Hering BJ, Wease S, Naziruddin B, et al. Improvement in outcomes of clinical islet transplantation: 1999-2010. Diabetes care 2012;35:1436-45.

[3] Khosravi-Maharlooei M, Hajizadeh-Saffar E, Tahamtani Y, Basiri M, Montazeri L, Khalooghi K, et al. Islet Transplantation for Type 1 Diabetes: So Close and Yet So Far away. European Journal of Endocrinology 2015:EJE-15-0094.

[4] Brissova M, Powers AC. Revascularization of Transplanted Islets Can It Be Improved? Diabetes 2008;57:2269-71.

[5] Schuit FC, Huypens P, Heimberg H, Pipeleers DG. Glucose sensing in pancreatic $\beta$-cells a model for the study of other glucose-regulated cells in gut, pancreas, and hypothalamus. Diabetes 2001;50:1-11.

[6] Cantley J, Grey S, Maxwell P, Withers D. The hypoxia response pathway and $\beta$-cell function. Diabetes, obesity \& metabolism 2010;12.

[7] Emamaullee JA, Shapiro AJ. Interventional strategies to prevent $\beta$-cell apoptosis in islet transplantation. Diabetes 2006;55:1907-14.

[8] Carlsson P-O, Palm F, Andersson A, Liss P. Markedly decreased oxygen tension in transplanted rat pancreatic islets irrespective of the implantation site. Diabetes 2001;50:489-95.

[9] Pedraza E, Coronel MM, Fraker CA, Ricordi C, Stabler CL. Preventing hypoxia-induced cell death in beta cells and islets via hydrolytically activated, oxygen-generating biomaterials. Proceedings of the National Academy of Sciences 2012;109:4245-50.

[10] Pepper AR, Gala-Lopez B, Pawlick R, Merani S, Kin T, Shapiro AJ. A prevascularized subcutaneous device-less site for islet and cellular transplantation. Nature biotechnology 2015;33:518-23

[11] Hajizadeh-Saffar E, Tahamtani Y, Aghdami N, Azadmanesh K, Habibi-Anbouhi M, Heremans Y, et al. Inducible VEGF Expression by Human Embryonic Stem Cell-Derived Mesenchymal Stromal Cells Reduces the Minimal Islet Mass Required to Reverse Diabetes. Scientific reports 2015;5.

[12] Zhang N, Richter A, Suriawinata J, Harbaran S, Altomonte J, Cong L, et al. Elevated vascular endothelial growth factor production in islets improves islet graft vascularization. Diabetes 2004;53:96370.

[13] Golocheikine A, Tiriveedhi V, Angaswamy N, Benshoff N, Sabarinathan R, Mohanakumar T. Cooperative signaling for angiogenesis and neovascularization by VEGF and HGF following islet transplantation. Transplantation 2010;90:725-31.

[14] Kawakami Y, Iwata H, Gu YJ, Miyamoto M, Murakami Y, Balamurugan A, et al. Successful subcutaneous pancreatic islet transplantation using an angiogenic growth factor-releasing device. Pancreas 2001;23:375-81.

[15] Ludwig B, Rotem A, Schmid J, Weir GC, Colton CK, Brendel MD, et al. Improvement of islet function in a bioartificial pancreas by enhanced oxygen supply and growth hormone releasing hormone agonist. Proceedings of the National Academy of Sciences 2012;109:5022-7.

[16] Nadithe V, Mishra D, Bae YH. Poly (ethylene glycol) cross-linked hemoglobin with antioxidant enzymes protects pancreatic islets from hypoxic and free radical stress and extends islet functionality. Biotechnology and bioengineering 2012;109:2392-401.

[17] Maillard E, Juszczak M, Langlois A, Kleiss C, Sencier M, Bietiger W, et al. Perfluorocarbon emulsions prevent hypoxia of pancreatic $\beta$-cells. Cell transplantation 2012;21:657-69. 
[18] Çetinus ŞA, Öztop HN. Immobilization of catalase into chemically crosslinked chitosan beads. Enzyme and microbial technology 2003;32:889-94.

[19] Çetinus ŞA, Öztop HN. Immobilization of catalase on chitosan film. Enzyme and microbial technology 2000;26:497-501.

[20] Rao RR, Peterson AW, Ceccarelli J, Putnam AJ, Stegemann JP. Matrix composition regulates threedimensional network formation by endothelial cells and mesenchymal stem cells in collagen/fibrin materials. Angiogenesis 2012;15:253-64.

[21] De Leu N, Heremans Y, Coppens V, Van Gassen N, Cai Y, D’Hoker J, et al. Short-term overexpression of VEGF-A in mouse beta cells indirectly stimulates their proliferation and protects against diabetes. Diabetologia 2014;57:140-7.

[22] Bayramoglu G, Karagoz B, Yilmaz M, Bicak N, Arica MY. Immobilization of catalase via adsorption on poly (styrene-d-glycidylmethacrylate) grafted and tetraethyldiethylenetriamine ligand attached microbeads. Bioresource technology 2011;102:3653-61.

[23] Yang HS, Bhang SH, Hwang JW, Kim D-I, Kim B-S. Delivery of basic fibroblast growth factor using heparin-conjugated fibrin for therapeutic angiogenesis. Tissue Engineering Part A 2010;16:2113-9.

[24] Rajan N, Habermehl J, Coté M-F, Doillon CJ, Mantovani D. Preparation of ready-to-use, storable and reconstituted type I collagen from rat tail tendon for tissue engineering applications. Nature protocols 2006;1:2753-8.

[25] Jaffe EA, Nachman RL, Becker CG, Minick CR. Culture of human endothelial cells derived from umbilical veins. Identification by morphologic and immunologic criteria. Journal of Clinical Investigation 1973;52:2745.

[26] Malinda KM, Nomizu M, Chung M, Delgado M, Kuratomi Y, Yamada Y, et al. Identification of laminin $\alpha 1$ and $\beta 1$ chain peptides active for endothelial cell adhesion, tube formation, and aortic sprouting. The FASEB Journal 1999;13:53-62.

[27] Kaelin WG. The von Hippel-Lindau protein, HIF hydroxylation, and oxygen sensing. Biochemical and biophysical research communications 2005;338:627-38.

[28] MORITZ W, MEIER F, STROKA DM, GIULIANI M, KUGELMEIER P, NETT PC, et al. Apoptosis in hypoxic human pancreatic islets correlates with HIF-1 $\alpha$ expression. The FASEB Journal 2002;16:745-7.

[29] Bonakdar S, Emami SH, Shokrgozar MA, Farhadi A, Ahmadi SAH, Amanzadeh A. Preparation and characterization of polyvinyl alcohol hydrogels crosslinked by biodegradable polyurethane for tissue engineering of cartilage. Materials Science and Engineering: C 2010;30:636-43.

[30] Phelps EA, Headen DM, Taylor WR, Thulé PM, García AJ. Vasculogenic bio-synthetic hydrogel for enhancement of pancreatic islet engraftment and function in type 1 diabetes. Biomaterials 2013;34:4602-11.

[31] Vernon RB, Preisinger A, Gooden MD, D'Amico LA, Yue BB, Bollyky PL, et al. Reversal of diabetes in mice with a bioengineered islet implant incorporating a type I collagen hydrogel and sustained release of vascular endothelial growth factor. Cell transplantation 2012;21.

[32] Li Z, Guo X, Guan J. An oxygen release system to augment cardiac progenitor cell survival and differentiation under hypoxic condition. Biomaterials 2012;33:5914-23.

[33] Panarin E, Kalninsh K, Pestov D. Complexation of hydrogen peroxide with polyvinylpyrrolidone: ab initio calculations. European polymer journal 2001;37:375-9.

[34] Abdi SIH, Ng SM, Lim JO. An enzyme-modulated oxygen-producing micro-system for regenerative therapeutics. International journal of pharmaceutics 2011;409:203-5.

[35] Yoshimoto M, Sakamoto H, Shirakami H. Covalent conjugation of tetrameric bovine liver catalase to liposome membranes for stabilization of the enzyme tertiary and quaternary structures. Colloids and Surfaces B: Biointerfaces 2009;69:281-7. 
[36] Acharya J, Ghaskadbi S. Free Radicals and Islet Function. Systems Biology of Free Radicals and Antioxidants 2014:3339-60.

[37] Quintens R, Hendrickx N, Lemaire K, Schuit F. Why expression of some genes is disallowed in betacells. Biochemical Society Transactions 2008;36:300-5.

[38] Chung Y-I, Kim S-K, Lee Y-K, Park S-J, Cho K-O, Yuk SH, et al. Efficient revascularization by VEGF administration via heparin-functionalized nanoparticle-fibrin complex. Journal of Controlled Release 2010;143:282-9.

[39] Phelps EA, Templeman KL, Thulé PM, García AJ. Engineered VEGF-releasing PEG-MAL hydrogel for pancreatic islet vascularization. Drug Delivery and Translational Research 2013;5:125-36.

[40] Yang HS, La W-G, Bhang SH, Jeon J-Y, Lee JH, Kim B-S. Heparin-conjugated fibrin as an injectable system for sustained delivery of bone morphogenetic protein-2. Tissue Engineering Part $A$ 2010;16:1225-33. 


\section{Figure Legends}

Fig. 1. Fabrication and characterization of microparticles (MP). (A) Schematic of production steps. Core-shell structural MP were produced by the coacervation method and catalase was immobilized on their surface. (B) Representative SEM micrograph of MP. (C) Size distribution histogram of MP. Diameters were calculated for 250 particles by ImageJ. Immobilization of catalase on the surface of MP maintained its activity up to $40 \%$ for 14 days and changed the kinetic parameters $\left(\mathrm{K}_{\mathrm{m}}\right.$ and $\left.\mathrm{V}_{\mathrm{max}}\right)$. (D) Catalase activity during 14 days. Lineweaver-Burk plots for determination of kinetic parameters: (E) free catalase and (F) immobilized catalase. MP produced oxygen by decomposition of released $\mathrm{H}_{2} \mathrm{O}_{2}$ by conjugated catalase on the surface. (G) Detection of oxygen concentration for $1 \mathrm{mg} / \mathrm{ml}$ of microspheres in PBS at $37^{\circ} \mathrm{C}$. Measurements were made in an open system incubator set at environmental oxygen by PreSens noninvasive, ruthenium-based oxygen sensors. Values represent mean $\pm \mathrm{SD}, \mathrm{n}=3$.

Fig. 2. Oxygenation by microparticles (MP) decreased the hypoxic effect on the MIN6 cell-line in vitro. Cells $\left(3 \times 10^{3}\right)$ were seeded on a 24 -well plate and incubated under hypoxic $(5 \%$ oxygen tension) and normoxic (normal oxygen tension) conditions in the presence or absence of MP for 7 days. Under hypoxic conditions, there was a decreased MTS level along with increased LDH release $(P<0.005)$. These hypoxic effects were reduced in the vicinity of MP $(P<0.05)$. (A) MTS level, (B) LDH release normalized by DNA content. (C) Representative immunofluorescence images of HIF1- $\alpha$ translocation during hypoxic conditions. Values represent mean $\pm S D, n=3$. $* P<0.05, * * P<0.01, * * * P<0.005$. 
Fig. 3. Scaffold characterization for islets transplantation. (A) Representative SEM micrograph of the fibrin-heparin collagen scaffold. (B) Cumulative release (\%) of VEGF by ELISA from the fibrin-heparin/VEGF collagen scaffold at a $100 \mathrm{ng} / \mathrm{ml}$ loading concentration. Human umbilical vein endothelial cells (HUVECs) stained with acridine orange for tube formation assay and in terms of tube area per field as analysed by Image J. (C) Quantitative results of tube formation assay. Stained HUVECS in the samples with: (D) soluble VEGF as a control, (E) VEGF released on days 1, (F) 4 and (G) 7. Presence of heparin in the scaffold promoted angiogenesis and cell migration. (H and I) Hematoxylin and eosin (H\&E) staining of the harvested scaffold sections in the absence and presence of heparin. (J) CD31 immunohistochemistry of the harvested fibrinheparin/VEGF collagen scaffold after subcutaneous implantation. Conjugated heparin increased scaffold vascularization $(P<0.005)$. $(\mathrm{K})$ Area/vessel $\left(\mu \mathrm{m}^{2}\right)$ calculated by dividing the total vessel area (measured by Image J) by the number of vessels per field (in five fields of five tissue sections). Presence of heparin in the scaffold promoted angiogenesis and cell migration. (L) Schematic of the scaffold preparation for islet transplantation. Islet and microparticles (MP) with fibrinogen-heparin were loaded into the collagen scaffold and fixed within the scaffold by fibrin formation. (M) Representative SEM micrographs that show MP surrounded by fibrin fibers in the collagen scaffold. Values represent mean $\pm \mathrm{SD}, \mathrm{n}=3,{ }^{*} P<0.05, * * P<0.01, * * * P<0.005$.

Fig. 4. Oxygenation and angiogenesis induction simultaneously improved function of the transplanted islets. (A) Blood glucose (mg/dl). Mice from the islet/MP/VEGF group had lower blood glucose levels compared to the islet and islet/MP groups $(P<0.005)$ and islet/VEGF group ( $P<0.01)$. In this group, $83 \%$ of mice returned to euglycemia at $7.6 \pm 2.6$ days. (B) Percentage of euglycemic mice. (C) Body weight (g) during 30 days. (D) Intraperitoneal glucose tolerance test 
(IP-GTT) curve. (E) Area under curve (AUC) of the IP-GTT on the $30^{\text {th }}$ day post-alloxan injection (PAI). (F) Serum C-peptide (pM). The trend for weight gain, area under the curve (AUC) for IP-GTT and C-peptide concentration in islet/MP/VEGF group were similar to the normal group when compared with the other groups $(P<0.005)$. Harvested grafts from the islets/MP/VEGF group showed more vascularization compared to grafts from the islet and islet/MP groups $(P<0.01)$. $(\mathrm{G})$ Area per vessel $\left(\mu \mathrm{m}^{2}\right)$ calculated by dividing the total vessel area (measured by Image $\mathbf{J}$ ) to the number of vessels per field (in five fields of five tissue sections). (H) Representative images of hematoxylin and eosin (H\&E) staining and insulin immunohistochemistry of the harvested islets/MP/VEGF scaffold. Staining of the graft from islet/MP/VEGF group showed functional islets close to the vessel. Values represent mean $\pm \mathrm{SD}$, $\mathrm{n}=6$ per group. $* P<0.05, * * P<0.01, * * * P<0.005$. Tx: Transplantation. 
A

B
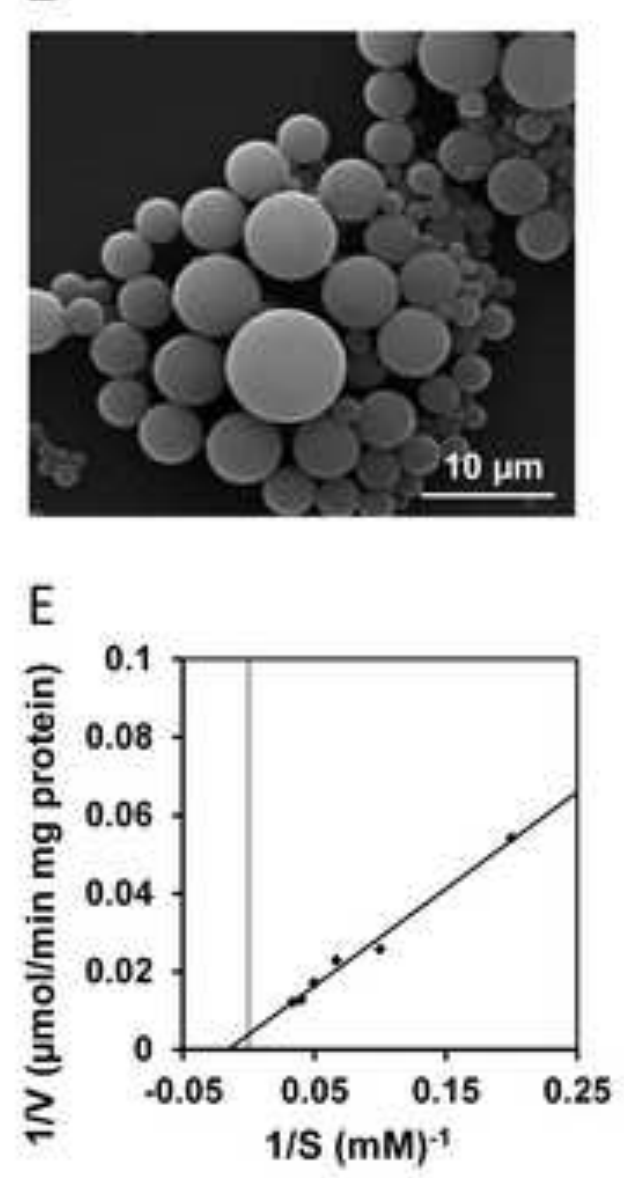

C
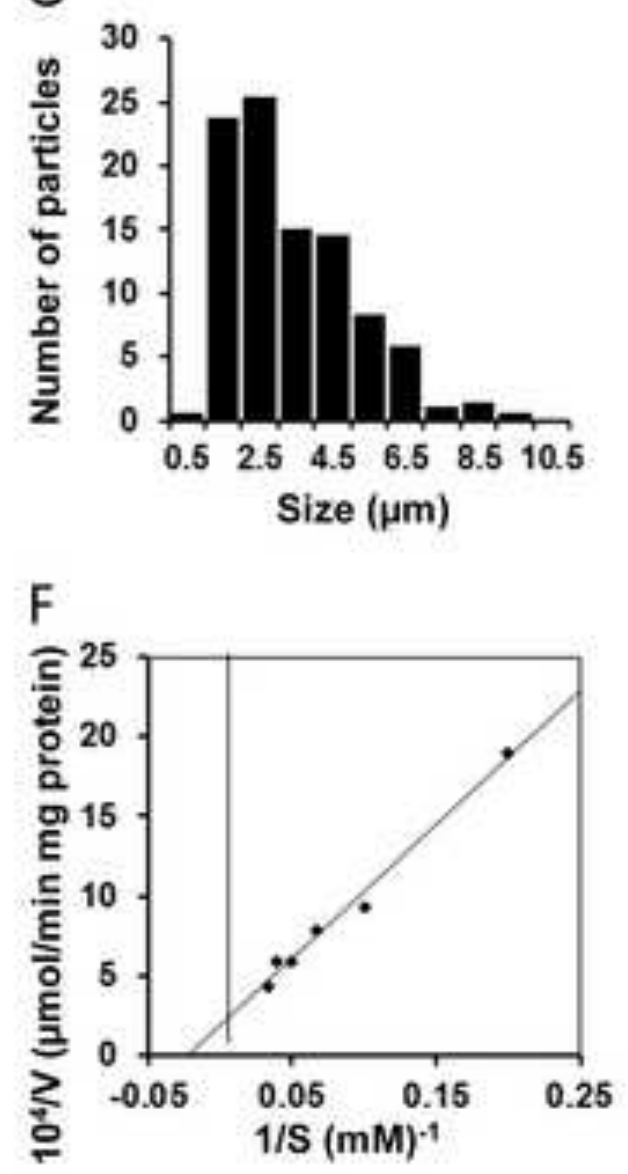

Catalase

immobilization

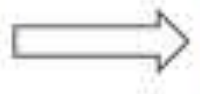

$f^{2}$
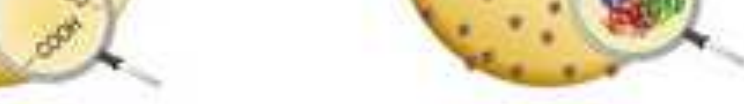

Catalase

D
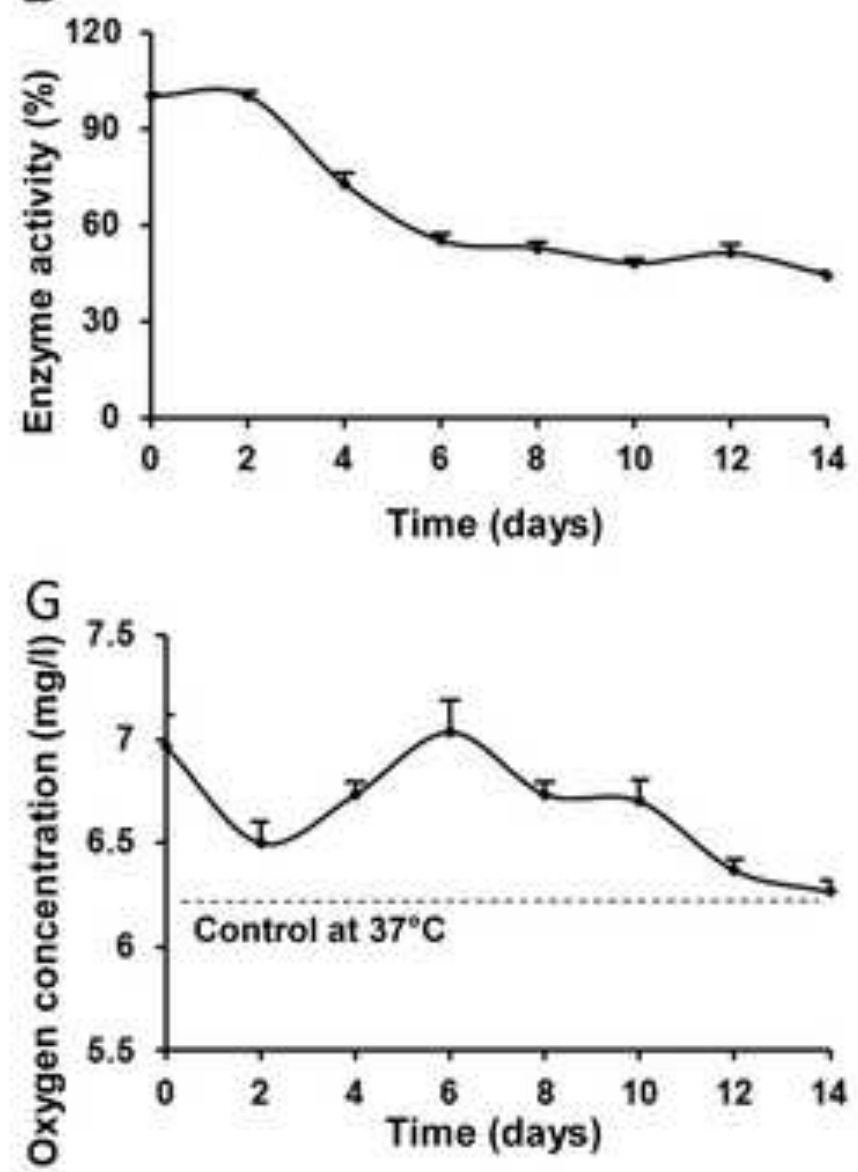
A

B

+ MP $\square-M P \square$

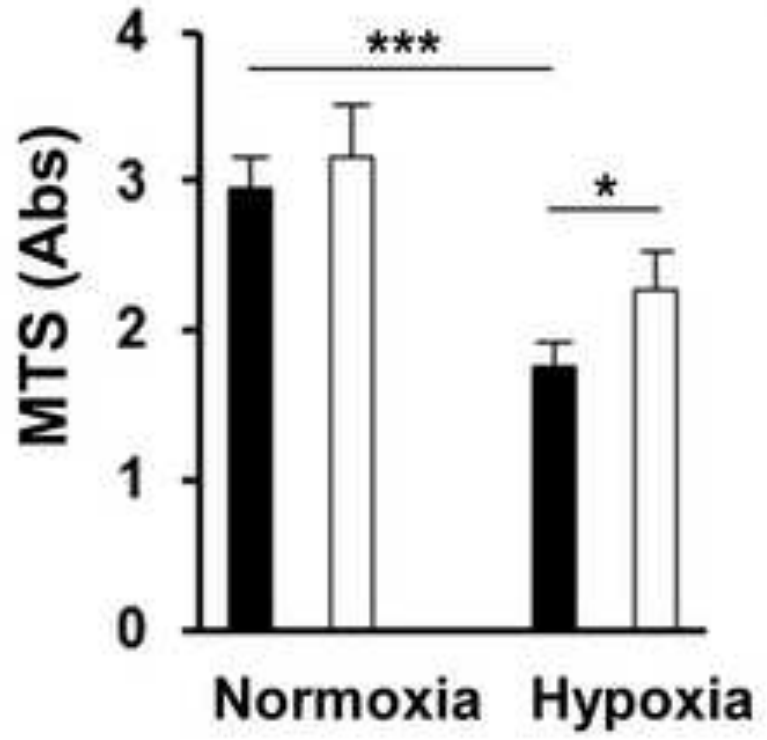

C
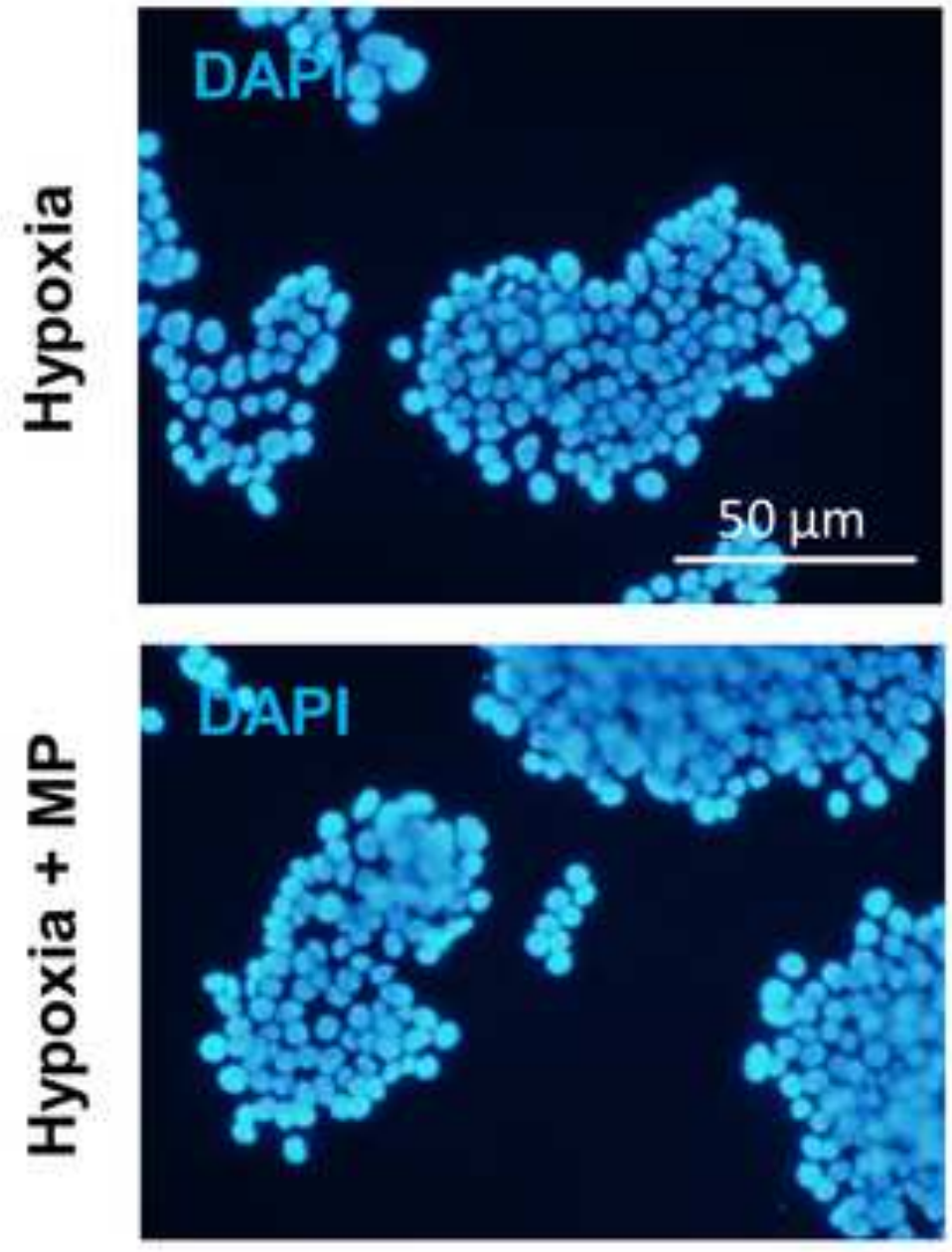
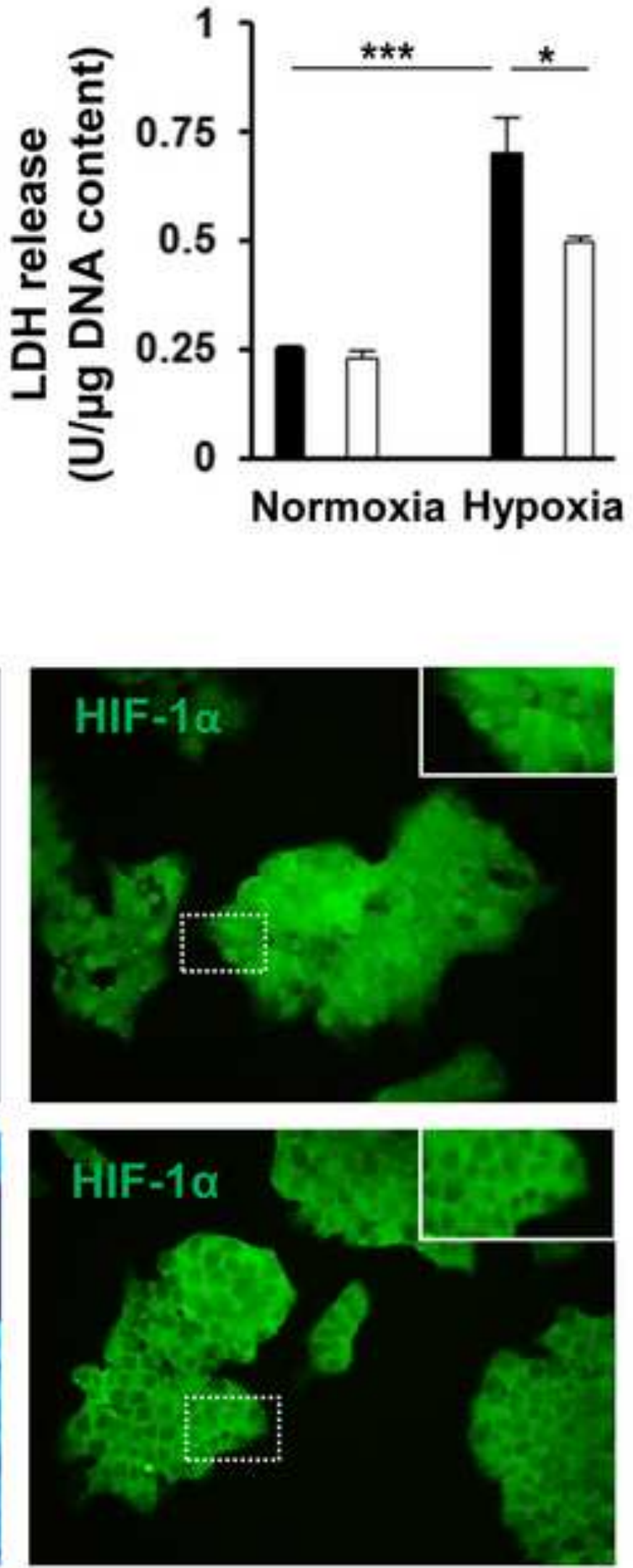

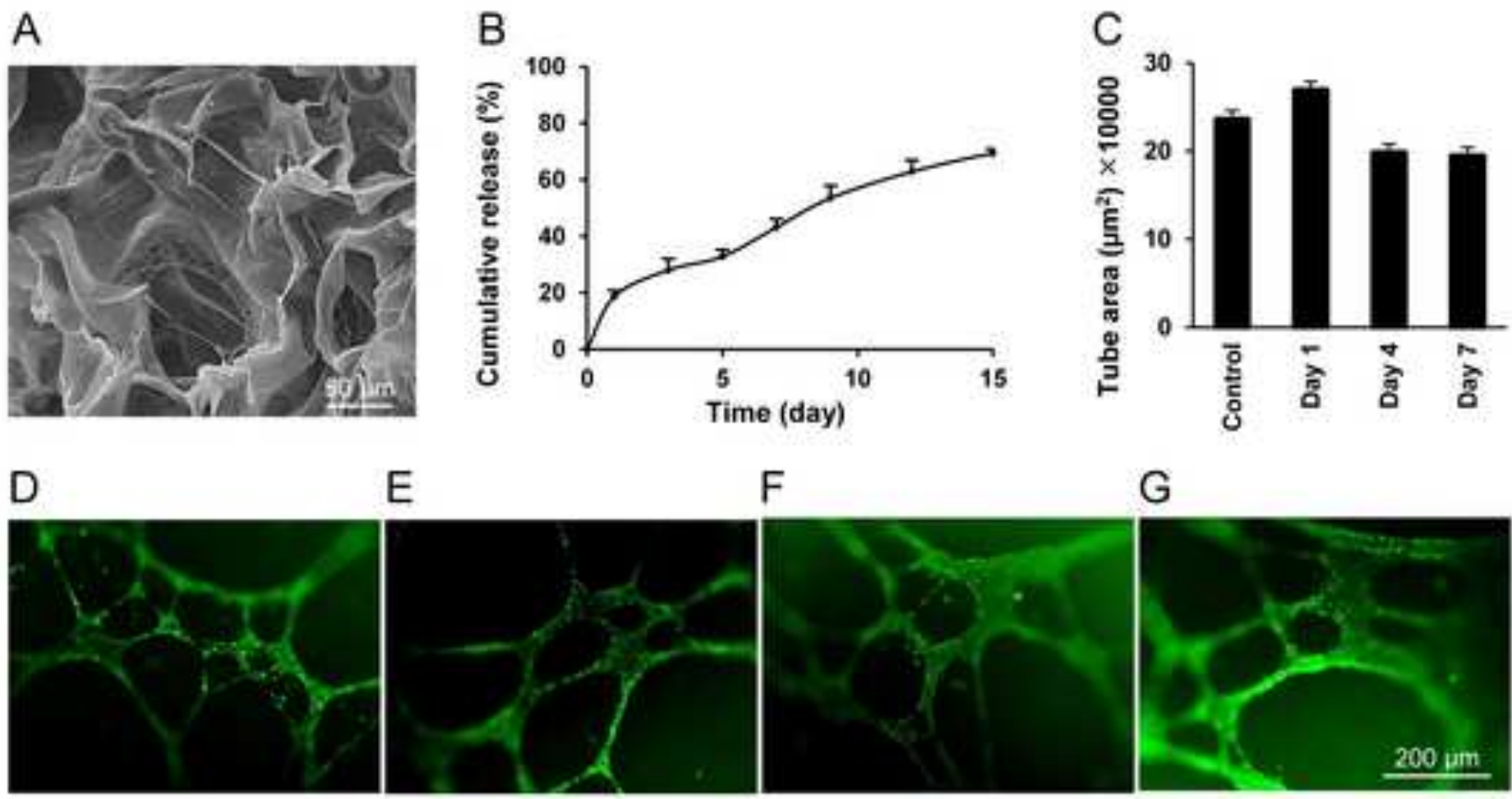

G
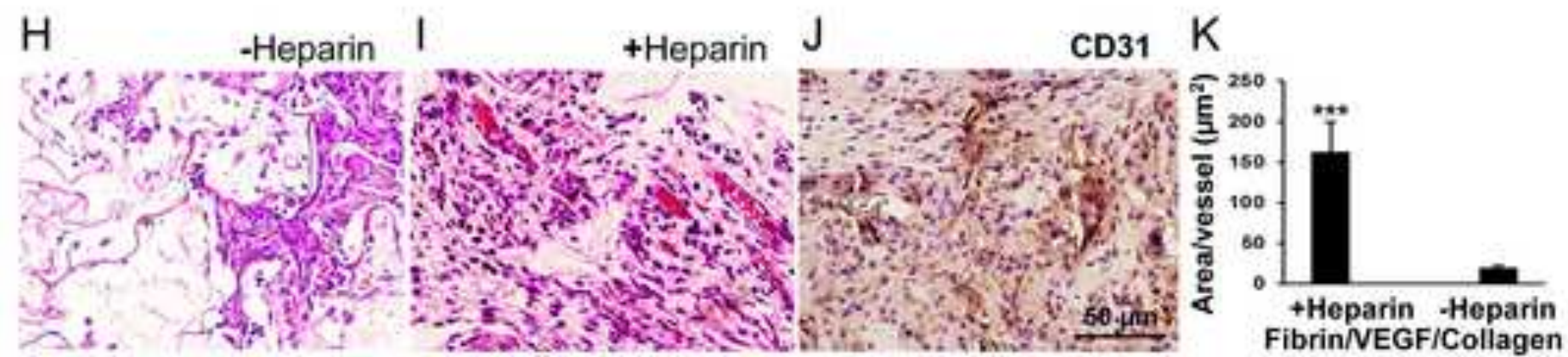

L

\section{Fibrin-heparin/VEGF}
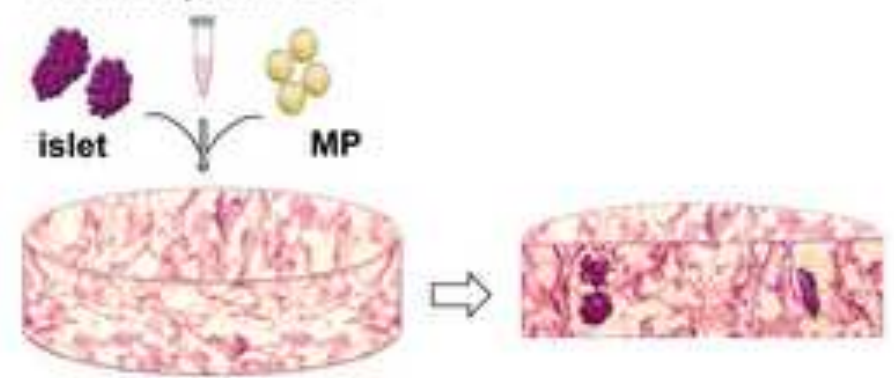

M

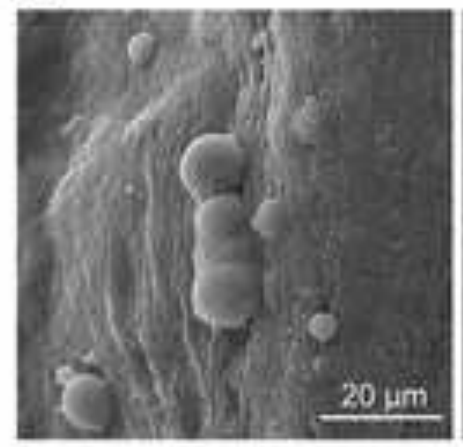


$\rightarrow-$ islet / MP / VEGF $\quad 0$-islet / MP $\rightarrow$ islet / VEFG

A

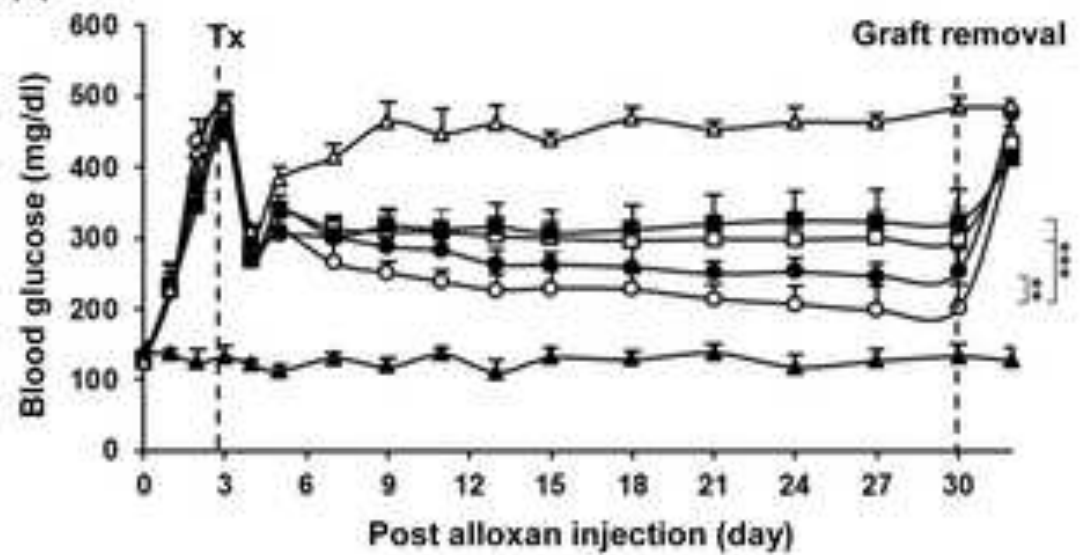

C

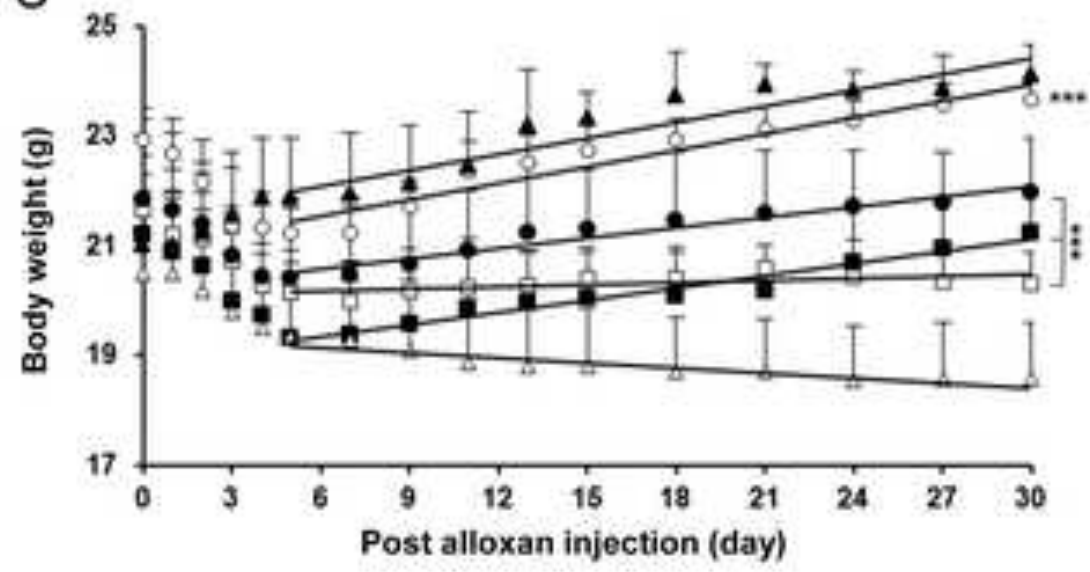

E

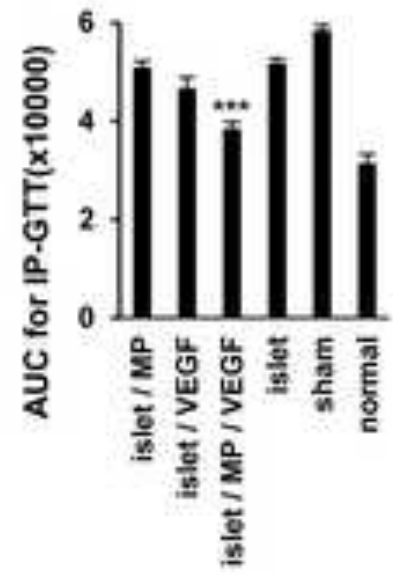

F

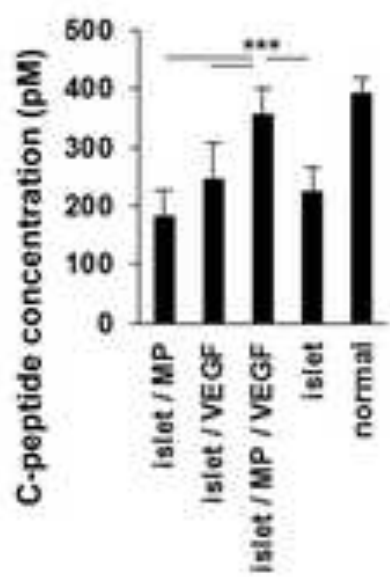

G

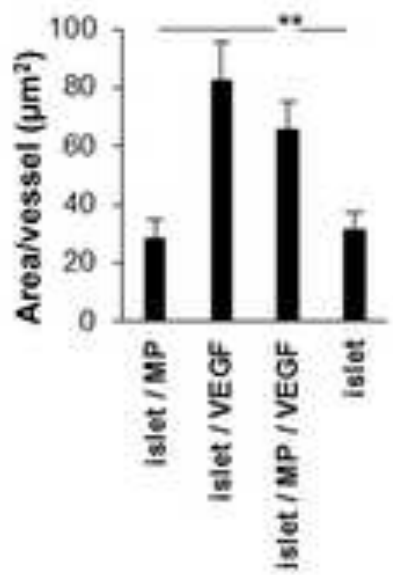

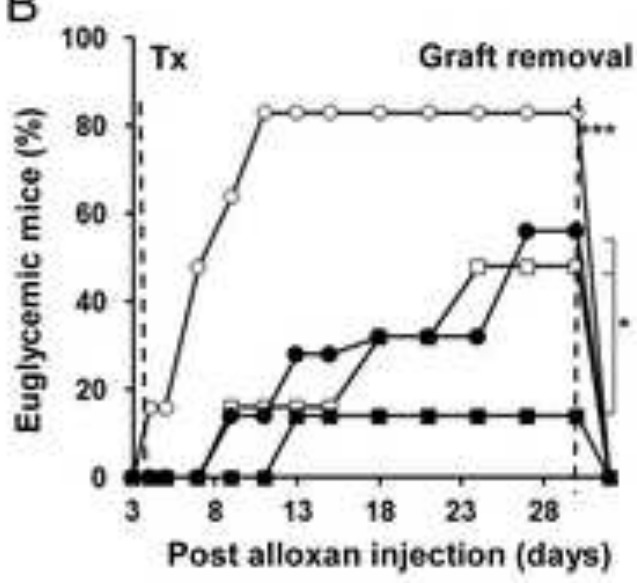

D

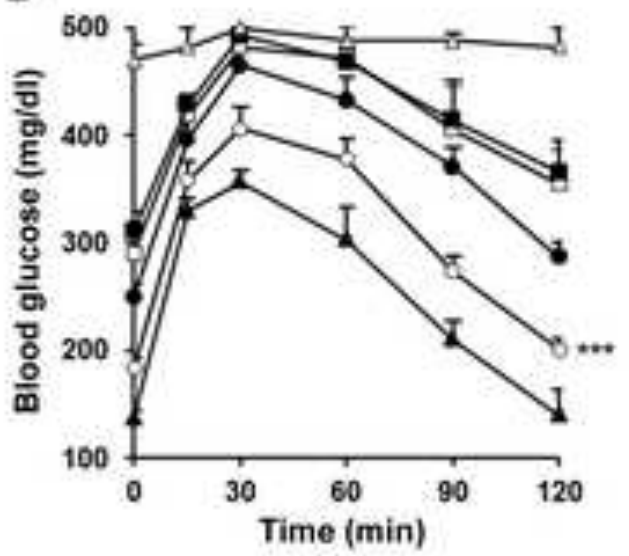

$\mathrm{H}$

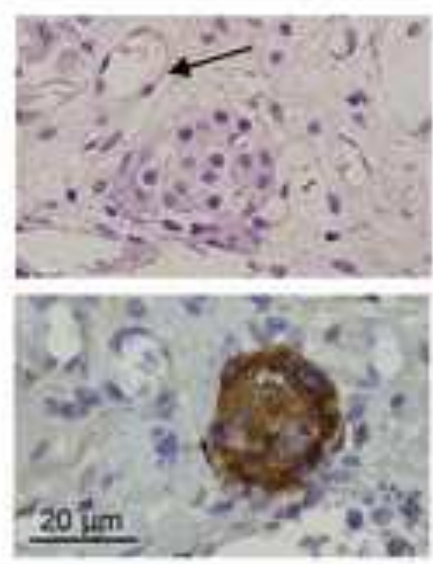

